sprats or mackerel, fish livers, egg yolk, milk and butter : if margarine is used, a brand containing added vitamins $\mathrm{A}$ and $\mathrm{D}$ should be employed. Cod liver oil and bone ash will also make good a deficiency in vitamin $\mathrm{D}$, calcium and phosphorus. As regards milk, the circular urges local authorities to take every opportunity of directing attention to the merits of milk as a food and of stimulating its increased use as an article of diet for children.

\section{Costs of Electricity Supply and Distribution}

Is an endeavour to foretell the future of electricity supply and distribution in Great Britain, Mr. J. M. Kennedy and Miss D. M. Noakes have made an elaborate analysis of the statistical returns issued by the Electricity Commissioners during the last ten years. They explained the conclusions arrived at in a paper read to the Institution of Electrical Engineers on January 26. They divide the capital invested into two parts, the first giving the costs of generation and the second the costs of distribution. The results show that the distribution side of electric supply is becoming the more important. They have also reviewed the revenue derived from the sales of electricity and allocated it between generation and distribution expenses. The figures show that although the efficiency of generation has increased materially, there has been little, if any, improvement in distribution efficiency. The cost per kilowatt installed during the last ten years has diminished from $£ 25$ to $£ 20$. This is probably due to the increase in the size of the turbine and boiler units installed. If it is assumed that the percentage of spare plant required would be 83 without the grid and 20 with the grid, the amount of spare plant released in five years time would be sixty million pounds in capital. As the sales of units per pound of distribution capital increase, the ratio of the distribution costs to the total costs decreases substantially. Whilst the distribution capital is increasing at the rate of 18 millions a year, the generation capital is only increasing at the rate of 7 millions. The authors state that if the companies offered sufficiently attractive tariffs, there seems no reason why the total domestic consumption should not be twice the present total sales for all purposes. If company control is decided on, a satisfactory scheme for the regulation of prices and dividends will have to be established. Any undue increase in the average remuneration of capital will inevitably keep up the price of electricity and retard development.

\section{Image of the Physical World in Cinematography}

THe two dimensional world of light and shadow projected upon the screen of a cinema theatre is something quite unique and is essentially different from our own material world of reality. In Scientia for January, Mr. Torahiko Terada states that future cinema techniques could be anticipated by a careful study of these two kinds of worlds. He considers that the marvels of the cinema film depend mainly on the element of time. When the relative scale of time in the physical world and the screen world is changed we receive a shock. For example, we can see the seed of a flower growing up into full blossom in a few minutes or a bullet emerging from the muzzle of a gun accompanied by a retinue of vortices and waves. This change in the scale of time brings with it the corresponding change in every physical quantity depending on the time. When a scene of a collapsing brick chimney is projected with half the natural speed, its acceleration will only appear to be a quarter its natural value and the value of gravity will apparently be only a quarter its true value. C. F. Flammarion once dreamed of the possibility of reviewing the world's history in its reverse order by flying out of our earth with a velocity greater than that of light. The principle of relativity prohibits this, but, in the screen world, history may run easily in its reverse order. In our visual effect it is practically the perfect reversal of time. It may be considered a materialised extension of our memory. It is impossible to tell in what direction a pencil balanced on its point will fall but in the reversed film it will stand upright as nearly perpendicular as possible. On the other hand, in a reversed film we cannot tell the direction in which a billiard ball at rest on the table is going to move. The reversal of time as realised in the cinema is a straightforward denial of the second law of thermodynamics - the only law prescribing the sequence of the physical world.

\section{New Britain}

To those who believe that the present situation is a challenge to thought and that reconstruction demands fundamentally both clarity of thought and the readiness to discard preconceived ideas or established customs or institutions, when these stand in the way, the new quarterly journal, New Britain, should make a strong appeal. Its pages are characterised by a freedom from prejudice and a capacity for courageous and independent thought worthy of an organ aiming at national renaissance and in harmony with the spirit of the Oxford reformers to whom we owe the English Renaissance of the sixteenth century. Scientific workers will be particularly interested in the articles which attempt to assess the place of science in the new order. Mr. Gerald Heard, in his article on "Eugenics and the New Order", directs attention to the part which eugenics must play, pointing out that lack of will-power prevents use being made alike of the plans of leaders or the 'stones' provided by science. Prof. F. Soddy discusses the physical foundations of civilisation and the dangers attending a policy of drift and failure to abandon the old herd instincts of poverty and scarcity and methods of dominance based upon them. Dr. G. Scott Williamson in his article on "The Scientists' Outlook" deals particularly with the place of biological science in the new order of society and the dangers of palliatives as against a positive and thoroughgoing policy. The cultural aspects of science and its place among human values are discussed in thought-provoking essays by S. G. Hobson and Philip Mairet. The whole of the January-March issue places a welcome emphasis on the social and human values of science and the positive benefits which it might yet confer on mankind. 